\title{
As relações de poder entre o coordenador pedagógico e o diretor da escola: algumas considerações
}

\author{
Jane Cordeiro de Oliveira ${ }^{1}$
}

\section{RESUMO}

Este trabalho é parte de duas pesquisas qualitativas realizadas em 2009 e 2015, tendo como instrumento a entrevista semiestruturada com 12 coordenadores pedagógicos em 2009 e 18 coordenadores em 2015, atuantes em escolas públicas municipais da Cidade do Rio de Janeiro. $\mathrm{O}$ artigo discute os conflitos existentes nas relações de poder entre coordenador, professores e o diretor. As questões levantadas foram: Como o coordenador lida com os diretores e professores? Como as relações de poder interferem no seu trabalho? Os referenciais principais foram: Weber (2009), Barroso (2009), Polon (2009) e Souza (2006; 2012). As relações verticais presentes no cotidiano escolar revelam o poder implícito em categorias como: mediação, afetividade, autonomia e parceria são decorrentes da posição intermediária que o coordenador ocupa na hierarquia da gestão escolar.

Palavras-chave: Coordenador Pedagógico. Relações de poder. Mediação.

\section{The power relations between the pedagogical coordinator and} the director: some considerations

\section{ABSTRACT}

This paper is part of two qualitative researches conducted in 2009 and 2015, in Rio de Janeiro city. Our questions: How does the pedagogical coordinator deal with the directors and teachers? How do the power relations influence his or her work? We used the semi-structured interview as data collection instrument with 12 pedagogical coordinators in 2009 and with 18 coordinators in 2015. The paper discusses the existing conflicts in the power relations between the coordinator and the director

1 Doutora em Educação Brasileira pela Pontifícia Universidade Católica do Rio de Janeiro (PUC-Rio). Professora de Geografia em escola pública municipal da Cidade do Rio de Janeiro. E-mail: janecoliveira@yahoo.com.br/ 
in two different moments of municipal public school policies. The most important references that dialogue with this paper are: Weber (2009), Barroso (2009), Polon (2009) and Souza (2006; 2012). The data revealed that the vertical relations present in school routine show implicit power disputes in the categories raised by the interviewees, such as "affectivity", "autonomy" and "partnership", resulting from the mediator position of the pedagogical coordinator in the hierarchy of school administration.

Keywords: Pedagogical Coordinator. Power relations. Mediation.

\section{Las relaciones de poder entre el coordinador pedagógico y el director de la escuela: algunas consideraciones}

\section{RESUMEN}

Este artículo es parte de dos investigaciones cualitativas conducidas en 2009 y 2015, en la ciudad de Rio de Janeiro. Nuestras cuestiones: ¿Cómo el coordinador trata con los directores y con los profesores? ¿Cómo las relaciones de poder interfieren en su trabajo? Utilizamos la entrevista semiestructurada como instrumento de colecta de datos, realizada con 12 coordinadores pedagógicos en 2009 y con 18 coordinadores en 2015. El artículo discute los conflictos existentes en las relaciones de poder entre el coordinador y el director en dos momentos diferentes de las políticas vigentes en las escuelas públicas municipales. Los referenciales principales que dialogan con este estudio son: Weber (2009), Barroso (2009), Polon (2009) y Souza (2006; 2012). Los datos revelaron que las relaciones verticales presentes en el cotidiano escolar revelan disputas de poder implícitas en las categorías levantadas por los entrevistados como: "afectividad", "autonomía" y "colaboración", resultantes de la posición mediadora del coordinador pedagógico en la jerarquía de la gestión escolar.

Palabras-clave:coordinador pedagógico. relaciones de poder. mediación.

\section{Introdução}

Este artigo é parte integrante de duas pesquisas de cunho qualitativo, realizadas em 2009 e 2015 (OLIVEIRA, 2009; 2015). Temos como objetivo discutir os conflitos existentes nas relações de poder entre o diretor e o coordenador pedagógico e, entre o coordenador e os profes- 
sores, a partir dos relatos dos entrevistados. Foram abordadas questões referentes às relações interpessoais, socioafetivas e de parceria entre o coordenador e o diretor da escola (PLACCO; SOUZA, 2012).

$O$ contexto que apresentamos está relacionado à constituição da equipe de gestão existente nas escolas públicas municipais da Cidade do Rio de Janeiro. Esta equipe é formada pelo diretor, diretor-adjunto e coordenador pedagógico. Percebemos que a posição hierárquica ocupada por cada um de seus membros foi estabelecida em documentos oficiais (RIO DE JANEIRO,1998a; 1998b). Estes regulamentam as funções e as tarefas de cada um dos membros da equipe de gestão escolar. 0 diretor ocupa a primeira posição, sendo o responsável administrativamente pela escola e assume a liderança dos profissionais que nela trabalham. O diretor-adjunto é o substituto imediato do diretor em seus impedimentos, o auxiliando nas atividades administrativas da escola. Ocupando a terceira posição, está o coordenador pedagógico que é o gestor das atividades pedagógicas da escola, cujas tarefas são: acompanhar o processo de avaliação e desempenho dos alunos e da escola, dinamizar o projeto pedagógico, divulgar junto aos professores as diretrizes e comunicados vindos da Secretaria Municipal de Educação - SME (RIO DE JANEIRO, 1998b).

Utilizamos a metodologia qualitativa, cujo instrumento foi a entrevista semiestruturada, para responder às seguintes questões: Como os coordenadores pedagógicos vivenciam questões relacionadas a sua identidade no cotidiano de trabalho da escola? Como acontecem as relações de poder entre coordenadores e diretores e entre coordenadores e professores? É possível perceber a existência de autonomia no trabalho desenvolvido pelos coordenadores pedagógicos na escola?

A primeira parte deste trabalho compreende a apresentação do problema e da metodologia utilizada nas duas pesquisas. A segunda parte mostra as falas dos coordenadores pedagógicos que relatam suas experiências a respeito das relações e conflitos de poder entre ele e o diretor e entre ele e os professores. A terceira parte refere-se aos dilemas enfrentados pelos coordenadores em relação à sua identidade e dos desafios que surgem no exercício das tarefas que ele executa na escola e sobre o contexto de autonomia ao executar as atribuições que lhes cabem na organização escolar. 
As considerações finais revelam que o coordenador pedagógico executa muitas tarefas que não fazem parte de suas responsabilidades e atribuições, mas, que acaba as assumindo para o bem da organização escolar, juntamente com as opiniões dos mesmos a respeito da sobrecarga de trabalho que acabam sofrendo. Percebeu-se que a questão relacional permeia as posições hierárquicas e de poder existentes entre o coordenador pedagógico e o diretor, como parceiros, porém, com alguns conflitos. Nas questões que envolvem o relacionamento entre o coordenador e os professores também percebemos haver relações de poder estratificadas de forma explícita e implícita, de acordo com os relatos dos entrevistados. Explícita porque alguns entrevistados afirmam que impõem aos professores a hierarquia de poder, em outros depoimentos, esta hierarquia não se apresenta de forma evidente.

\section{Caminhos metodológicos}

No processo de desenvolvimento da pesquisa qualitativa, utilizamos a entrevista semiestruturada como instrumento de coleta de dados e a análise de conteúdo para a compreensão dos textos resultantes das transcrições das entrevistas. Entendemos que a entrevista é um método eficaz na coleta de dados de cunho pessoal e que não poderiam ser observados por outros instrumentos (ZAGO, 2003). Para Lüdke e André (1986) é fundamental que o pesquisador apresente um roteiro pré-estabelecido de perguntas que o auxiliem na abordagem junto aos informantes.

Primeiramente, entrevistamos 12 coordenadores pedagógicos em 2009 e 18 coordenadores em 2015. Todos os participantes em ambas as pesquisas são atuantes em escolas públicas municipais da Cidade do Rio de Janeiro. O campo da primeira pesquisa foram as escolas públicas municipais de ensino fundamental, localizadas nos bairros de Jacarepaguá e Barra da Tijuca, zona oeste da Cidade do Rio de Janeiro. Na segunda pesquisa, nosso campo abrangeu as escolas localizadas nos seguintes bairros: Taquara, Praça Seca, Freguesia, Curicica, Barra da Tijuca, Vargem Grande, Lagoa, Tijuca, Rio Comprido e Copacabana.

A entrevista trouxe a possibilidade de conhecer detalhadamente a rotina do trabalho do coordenador pedagógico, juntamente com as suas percepções a respeito das atividades que desenvolve na escola, assim como analisar relatos do cotidiano da gestão e das relações de 
poder implícitas entre diretor-coordenador pedagógico e entre coordenador pedagógico-professores. A análise de conteúdo (OLIVEIRA, et. al., 2003) nos permitiu conhecer a fundo, nos depoimentos dos coordenadores pedagógicos, suas considerações a respeito das relações de poder existentes no espaço da escola e os dilemas existentes no cotidiano de trabalho.

O contexto das políticas, observado na pesquisa de 2009, demonstrou que a SME, através do sistema de ciclos de formação, dava relevância para a construção do projeto político pedagógico, para a afirmação da identidade cultural das escolas e para a avaliação discente através de atividades e registros em relatórios. Na pesquisa realizada em 2015, priorizava-se a uniformização curricular, o sistema de premiação por desempenho, a avaliação em larga escala e o controle maior do trabalho desenvolvido em sala de aula através de materiais pedagógicos padronizados. O projeto político pedagógico e a identidade cultural da escola foram deixados de lado.

\section{O contexto das relações de poder entre coordenador e diretor}

Para Barroso (2005), o poder é a alma das organizações, onde estas são instrumentos para a realização de fins através do comando de outros, utilizando-se dos mais diversos meios. As relações de poder, implícitas na escola, estão diretamente ligadas à hierarquia das funções desempenhadas pelos profissionais que nela trabalham. Souza (2012) afirma que, em relação ao diretor e ao coordenador, as relações de poder existentes se confundem com a atividade política exercida na escola, pois, envolvem categorias como: socialização, disputas e diálogo com vistas ao controle de poder.

O coordenador pedagógico ocupa uma posição intermediária na hierarquia escolar, por isso, este exerce e sofre, ao mesmo tempo, influências das estratificações de poder contidas nas relações sociais entre ele e a comunidade escolar. $\mathrm{O}$ coordenador está exposto a conflitos entre ele e o diretor, podendo optar por aplicar estratégias de aproximação de cunho relacional, munindo-se dos três tipos de perfil de liderança em gestão escolar: liderança transformacional que trata do enfrentamento de desafios com uma perspectiva inovadora na gestão de pessoas; liderança transacional que tem como foco as interações entre as pessoas promovendo ações para o alcance de metas e objetivos e a 
liderança compartilhada que trata da liderança distribuída entre aqueles que dela participam fazendo com que todos se integrem nas ações da escola (LÜCK, 2008). Polon (2009) afirma que a predominância da liderança relacional é bastante significativa e Souza (2006) defende que a gestão escolar, por sua natureza política, funde-se com o poder, de acordo com os relatos dos entrevistados.

A gestão escolar, em primeiro lugar, cabe aos diretores, em seguida, aos diretores-adjuntos e, numa escala de menor influência, aos coordenadores pedagógicos. Na estrutura hierárquica da escola, encontramos relatos que indicam uma cumplicidade entre o diretor e coordenador no exercício de seu trabalho.

A gestão é uma gestão pedagógica, mas, ela (a diretora) deixa muito à vontade a coordenação para exercer o seu papel. Então é importante que a escola deixe o coordenador praticando a sua função, que é esse elo entre o fazer e o acontecer. Não ficar desviando os papéis porque quando você vai ver no final do dia, muitas vezes, em muitas escolas, quando você vai fazer a avaliação do seu dia, você vai ver que no pedagógico você praticamente não fez nada. E aqui na escola eu tenho essa liberdade do meu dia ser destinado a dedicar praticamente cem por cento ao pedagógico ${ }^{2}$ [Rosana ${ }^{3}$, 2009].

A coordenação tem que ser um casamento também, com a direção e com os professores. A gente não faz parte nem da direção e nem do corpo de professores. Eu sou um elemento solto neste grupo que vai fazer justamente esta ponte, esta ligação entre estes dois grupos bem distintos que é a direção e o corpo docente. Então, eu vejo a minha função hoje como uma integração [Francisca, 2015].

Os relatos ora apresentados revelaram uma parceria entre o diretor e o coordenador pedagógico, distanciando este último do corpo de professores e o aproximando da equipe de gestão. Os coordenadores entrevistados em 2015 relataram que, nas atuais políticas, eles também lidam de forma mais evidente com relações de poder externas à escola: a Coordenadoria Regional de Educação (CRE) e a Secretaria Municipal de

2 Neste artigo respeitamos o formato das falas dos entrevistados.

3 Todos os nomes dos coordenadores pedagógicos citados neste artigo são fictícios, obedecendo a ética de preservação do anonimato dos entrevistados. 
Educação (SME). Nestas políticas, as indicações da SME são mais explícitas, visando maior controle sobre as unidades escolares.

A CRE marcou uma reunião para mim no turno da tarde, quando estou em sala de aula, eu ligo dizendo que não posso ir, porque estou em turma nesse horário. Elas respondem: "Você tem que ligar para outras escolas para ver se alguma coordenadora que possa trocar com você [...]" [Luana, 2015].

Os coordenadores entrevistados em 2009 e, em 2015, disseram que as relações de poder entre o diretor e o coordenador são suavizadas ao classificarem o diretor como: "amigo", "cúmplice" e "parceiro". Eles se consideram parceiros dos diretores no exercício das tarefas que visam manter a organização escolar e fazer com que os professores executem as ações esperadas junto aos alunos e, junto às demandas oriundas da CRE e SME.

Nossa relação foi sempre de muito respeito, realmente é uma equipe [Solange, 2009].

A diretora pede para que eu fique porque eu somo com ela, o braço direito [Elena, 2009].

A direção sempre procura estar atenta às solicitações e a nossa secretaria tem acesso livre [Sarah, 2015].

As relações de trabalho entre o coordenador e o diretor são evidenciadas pelos relatos que enfatizam: "equipe", "braço direito", "estar atenta às suas solicitações" e permite "o acesso livre à secretaria da escola", onde fica a mesa do diretor.

Acho assim: é um apoio para os professores, procurando mediar, facilitar o trabalho deles, que tem um trabalho bastante árduo em sala de aula, que tem uma estrutura não adequada. Então, estou sempre tentando ser um facilitador desse processo [Virna, 2015].

Os coordenadores entrevistados, em sua maioria, definem sua relação com o diretor da escola como: "parceria", "equipe", "aliado", "braço direito da direção", "elemento solto". Os coordenadores pedagógicos sentem-se comprometidos diretamente com os diretores que os indicaram para a função e/ou com os professores da escola que apoiaram sua indicação. Todos os coordenadores entrevistados nas duas pesquisas demonstraram ter uma imagem positiva dos diretores com quem traba- 
Iham, porém, no decorrer da entrevista, alguns revelaram a existência de relações verticais hierárquicas de poder conflituosas entre o diretor e o coordenador pedagógico.

\begin{abstract}
Eu tenho uma relação parceira. Eu tenho apoio da direção, e sou ouvida. Não só sou ouvida como também a direção pede a minha opinião para determinadas coisas que elas querem fazer, há uma parceria muito legal. Há um grau de amizade e de envolvimento e por isso estamos juntas [Rosana, 2009].

Eu trabalho muito sozinha. Todo o mundo me pede ajuda, ninguém me ajuda, e eu não estou disponível [Luana, 2015].
\end{abstract}

Rosana define como "parceria" o fato de ser ouvida pela direção de sua escola e de ser consultada sobre algumas decisões que são tomadas pela mesma. Outros coordenadores também se definem como "parceiros" do diretor. Já Luana refere-se ao seu relacionamento de parceria com a direção da escola como: "trabalhar sozinha", revelando que há certo conflito no trabalho feito por ela na coordenação.

\footnotetext{
Compram todos os projetos que eu trago, e que as professoras abraçam, elas estão abraçando juntas. São parceiras, muito parceiras [Shana, 2009].

Ela vê todos os projetos, participa de todos os projetos, então é uma parceira dentro da escola [Aline, 2009].
}

No campo da gestão educacional, a parceria é definida como a maneira que cada parceiro mantém sua identidade no desenvolvimento de um projeto comum, com claras responsabilidades, considerando os limites de cada um, desenvolvendo um trabalho em colaboração, sem a perda da autonomia (ASSIS; MENDES; ALMEIDA, 2011).

O termo "parceria", no campo da administração, é caracterizado como a união, não de pessoas, e sim, de instituições, para a realização de projetos de grande porte e atuações em diversas áreas: social, econômica, jurídica, etc. A noção de parceria passou a ser utilizada para definir a relação contratual estabelecida entre governos e empresas privadas, fundações ou organizações não-governamentais (PIERRO, 2001). A parceria é definida pelos entrevistados como uma relação de cumplicidade entre o coordenador e o diretor da escola, 
a respeito do trabalho que ambos exercem. A relação com o diretor também é definida como uma aliança política construída nas relações estabelecidas na escola (SOUZA, 2012). Apresentamos as definições de "parceria" oriundas dos entrevistados:

É uma aliada. O que me facilita muito e eu ganho credibilidade dentro do grupo [Aline, 2009].

Nossa relação foi sempre de muito respeito, realmente é uma equipe [Solange, 2009].

A diretora pede para que eu fique porque eu somo com ela, o braço direito [Elena, 2009].

Fazemos reuniões de equipe, sempre [Selma, 2015].

Entretanto, o coordenador pedagógico é consciente de sua posição na estratificação de poder da escola. Os termos "parceiro" e "aliado" indicam que há uma relação de afetividade com a pessoa que representa o "poder" na escola, no caso aqui, o diretor. Souza (2012) define o diretor como o chefe da repartição pública, uma autoridade dominadora. O coordenador pedagógico situa-se, juntamente com o diretor-adjunto, numa posição secundária na hierarquia da gestão escolar, conforme o depoimento de Rosane demonstra.

Eu sou a mais antiga da escola. Mas, eu sei até onde eu posso ir. Eu sei qual é meu papel e sei qual é o papel da direção. Elas não passam por cima de mim, e nem eu delas [Rosana, 2009].

Voltando à questão da hierarquia, Rosana demonstra com clareza a sua posição: hierarquicamente abaixo do diretor e do diretor-adjunto. Ela reconhece a autoridade do diretor e a respeita. A coordenadora revela: "Eu sei qual é meu papel e sei qual é o papel da direção". No entanto, ela define "parceria" como aquele que faz parte da "equipe", considerando-se importante para o bom andamento do trabalho escolar.

Os coordenadores destacam que a amizade faz parte do relacionamento com a direção da escola:

Há um grau de amizade e de envolvimento e por isso estamos juntas [Rosana, 2009].

...somos amigas há dez anos [Zélia, 2009].

Nossa relação é muito boa porque somos muito amigas [Solange, 2009]. 
Nessa amizade há reciprocidade muito grande e respeito profissional [João, 2009].

Estou numa equipe muito boa [Samantha, 2015].

O que me fez aceitar essa função foi o meu relacionamento com a diretora [...] é uma pessoa de bom coração [Ângela, 2015].

Percebe-se nos relatos ora apresentados que a convivência diária fortalece os laços afetivos existentes entre a equipe gestora da escola. O cotidiano é fundamental para a construção destes relacionamentos, possibilitando observar os papéis desempenhados por cada um dos membros da equipe gestora, assim como os conflitos existentes entre eles.

A rotina de convivência no espaço de trabalho torna-se uma ferramenta de construção de relacionamentos, compromisso e afetividade. Barreto e Silva (2008) afirmam que a afetividade é uma estratégia utilizada pelo coordenador pedagógico para a manutenção e fortalecimento da sua posição hierárquica na gestão escolar. Na posição de mediador das relações verticais na escola, entre direção e professores, os dados revelaram que o coordenador pedagógico trabalha fundamentalmente com o perfil de liderança relacional, na medida em que estabelece vínculos afetivos tanto com o diretor quanto com os professores.

\section{As relações de poder entre o coordenador pedagógico e os professores}

No que diz respeito ao desempenho das tarefas exercidas pelo coordenador, uma delas, é liderar o desenvolvimento do trabalho pedagógico dos professores. Apresentamos como exemplo o depoimento da coordenadora Virna se vê como uma "facilitadora", ou seja, mediadora entre os professores e as novas políticas da SME. Os coordenadores entrevistados, na pesquisa de 2015, percebem-se como elemento intermediário entre a direção e os professores, como mediadores. A mediação, categoria que surge nas relações de poder entre o coordenador e os professores, pode ser definida como mediação socioafetiva ou relacional envolvendo as relações sociais e afetivas entre os docentes e o coordenador pedagógico (OLIVEIRA, 2015). O coordenador assume o papel de agente ativo na construção dos relacionamentos sociais na escola de forma que os liderados possam efetuar ações assertivas para 
o bom desempenho da escola, conforme defendem Del Prette e Del Prette (1998).

Às vezes, eu trato como mãe, dou bronca, tem umas (professoras) da minha idade, mas, tem umas mais novinhas, aí eu dou bronca, eu brigo mesmo (risos). Primeiro eu converso muito, dou as dicas para o trabalho [Solange, 2009].

Eu acho que me aproximo melhor delas (professoras). Eu não estou acima dos colegas, eu estou junto com elas para procurar fazer com que elas melhorem dentro da sala de aula [Samantha, 2015].

A coordenadora Solange define o seu relacionamento com as professoras assumindo o papel de "mãe severa", na tarefa de levar os docentes a executarem as ações esperadas pela gestão visando o bem da organização escolar (POLON, 2009). Entretanto, o coordenador demonstra o seu esforço em construir uma relação afetiva buscando facilitar seu relacionamento com os docentes, assim como Samantha se propõe a relacionar-se com as professoras de sua escola de forma a desempenhar o papel de "ajudadora".

Sadalla e Azzi (2004) afirmam que sentimentos emergentes entre o coordenador pedagógico e o grupo de professores envolvem, além dos sentimentos do grupo, os seus próprios, sem perder de vista o respeito à alteridade entre coordenador e professor. Assumindo o papel de "mãe" dos professores, a coordenadora Solange indica que o tempo do coordenador dedicado ao trabalho na escola, que são 8 horas por dia, gera vínculos comparados aos familiares.

O pessoal daqui é muito bacana, tem suas dificuldades porque lidar com ser humano é muito complicado; porque é melhor lidar com criança do que com adulto, mas, as meninas [professoras] daqui são muito bacanas então isso facilita. Eu acho que elas conseguem ver em mim não uma chefe autoritária, mandona, mas, uma colega, uma companheira. A gente divide coisas e, quando necessário, a gente partilha também algumas ordens que eu preciso que elas cumpram a tempo. Então, a parceria é boa [Zélia, 2009].

No depoimento ora destacado, Zélia assume o papel de "companheira das professoras". Segundo ela, isso facilita a construção das relações socioafetivas em sua escola. Ela busca camuflar a barreira hierárqui- 
ca, que, em sua opinião, a impediria de construir uma relação de amizade profissional com as professoras. Zélia procura evitar este estranhamento colocando-se como "uma colega", "uma companheira",na tentativa de minorar os efeitos do seu isolamento resultante do desempenho da função de coordenador. Ela tenta manter os mesmos laços de afetividade social com as professoras de sua escola. Neste caso, Zélia abre mão da atribuição de "fiscalizadora" ou de "cobradora das tarefas pedagógicas" para tornar-se "colega" das docentes. Rosana e Solange, ao contrário, assumem uma posição hierárquica mais explícita nos relacionamentos profissionais e afetivos com as professoras, com o objetivo de promover o cumprimento das normas estabelecidas pela SME. Lück (2006) afirma que a burocratização dos sistemas de ensino dificulta as relações entre aqueles que trabalham na escola, gerando estruturas hierárquicas unidirecionais. Zélia tenta evitar este distanciamento, negociando com os professores o seu espaço de atuação, ao contrário de Solange que se aproxima afetivamente dos professores, porém mantém sua posição hierárquica.

\section{A autonomia do coordenador pedagógico}

Quanto à autonomia, os coordenadores entrevistados informaram que não possuem autonomia para o exercício de trabalho na escola, outros afirmaram que possuem autonomia para trabalhar, porém necessitam da cumplicidade da direção. Os coordenadores citaram a autonomia como um fator importante para o desenvolvimento de suas atividades, visto os indícios de conflito entre coordenador e diretor. A autonomia de trabalho está diretamente relacionada com as relações sociais envolvendo confiança e amizade que os coordenadores declararam ter com os diretores de suas escolas.

A autonomia passa a ser considerada como um conceito importante na formação da identidade do coordenador, principalmente, considerando as relações de hierarquização vertical existentes na escola. Barroso (2005) mostra que o conceito "autonomia" tem certo grau de relatividade. $\mathrm{O}$ grupo ou o indivíduo pode agir por conta própria sendo responsável pelas decisões que toma no decorrer do trabalho que desempenha. Para o coordenador, que ocupa a posição intermediária na hierarquia de poder na escola, a autonomia de suas ações está diretamente ligada à sua relação socioafetiva com o diretor, isto é, como o diretor delega, ou não, "autonomia" de trabalho ao coordenador. 
Ela me dá liberdade [Aline, 2009].

Ela me auxilia muito e me dá "carta aberta" para trabaIhar dentro da escola [Elisa, 2009].

"Compram" todos os projetos que eu trago e que as professoras abraçam [Shana, 2009].

Ela coopera bastante com o trabalho que eu quiser fazer, ela dá apoio [Kátia, 2009].

Nem sempre a direção está disponível para sanar as dificuldades delas (professoras). Eu acho que essa função não está sendo valorizada [Luana, 2015].

O conceito "autonomia" está, de acordo com os entrevistados, relacionado com sentimentos de amizade entre o coordenador pedagógico e o diretor. As expressões: "dá liberdade", "coopera","compram todos os projetos" "dá carta aberta para trabalhar" são utilizadas pelos informantes para definir a autonomia concedida pela direção da escola ao coordenador para que ele possa executar o seu trabalho. Shana é a única que busca primeiramente o apoio dos professores na apresentação de seus projetos pedagógicos antes de levá-los à direção da escola, provavelmente, objetivando o apoio dos docentes para garantir a aprovação de seus projetos junto ao diretor. Luana, no entanto, percebe-se sobrecarregada porque nem sempre a direção está disponível para lhe dar apoio no decorrer do exercício das atividades de coordenação e junto ao seu trabalho com os professores.

Todas as duas [diretora e diretora-adjunta] gostam de supervisionar tudo e estão enfronhadas em todas as partes. E eu acho que para mim facilita o trabalho [Flávia, 2009].

Na questão de trabalho, eu tenho que passar tudo por ela [diretora]...ela me respalda, me apoia. [Laura, 2009].

Tanto no aspecto administrativo, quanto no pedagógico, não é o coordenador sozinho quem decide [...] nós temos uma relação de confiança entre a direção e a coordenação [João, 2009].

Eu tenho o apoio da direção e sou ouvida. [...] Eu sou a mais antiga da escola, mas eu sei até onde eu posso ir. Eu sei qual é o meu papel e qual é o papel da direção [Rosana, 2009].

Estes depoimentos apresentam, na ótica dos entrevistados, diretores que demonstram possuir um perfil centralizador demarcando sua 
posição diante do coordenador pedagógico. Para Lück (2006), a "falta de autonomia" demonstra um estilo de gestão comumente exercida na escola: linear, fragmentada, estabelecida de "cima para baixo" onde, o ato de administrar corresponderia ao ato de "comandar" e "controlar". Neste caso, a escola passa a ser o espaço de disputas de poder entre os membros da equipe gestora: diretor e coordenador pedagógico.

Os coordenadores demonstraram, primeiramente, apoiar o estilo de gestão de seus diretores, como uma atitude polida. Mas, no decorrer da conversa com a pesquisadora, algumas questões relacionadas a disputas de poder são reveladas como, por exemplo, o caráter centralizador de alguns diretores, e outros que exercem uma gestão de cunho mais democrático. Os depoimentos dos entrevistados nos permitiram observar como eles se sentem em relação a essa "falta de autonomia" ou, o que denominamos de "autonomia relativa" (OLIVEIRA, 2009).

\title{
As múltiplas atividades do coordenador pedagógico
}

O coordenador pedagógico, ao permanecer diariamente no espaço escolar, se depara com situações que fogem à rotina planejada onde ele, visando o bem da organização escolar, assume tarefas que não são de sua responsabilidade.

\begin{abstract}
A gente faz parte de uma equipe. Por muitas vezes, sou solicitada a fazer algo da parte administrativa e elas [direção] também me ajudam [Elza, 2009].

No momento estou ajudando a direção, mas, quando eu preciso, elas [a diretora e a diretora-adjunta] não esperam eu pedir. Elas estão lá junto comigo. Eu faço os meus planos, mas, quando a diretora tem que ir a uma reunião na CRE então eu fico sozinha e eu tenho que ficar atendendo telefone, abrindo escola, fechando escola, atendendo responsável, fazendo declaração e aí eu não faço o meu trabalho pedagógico [Shana, 2009].

Eu vou cumprimentar a diretora, a secretária, para ver se está tudo bem, verificar se houve algum problema [Samantha, 2015].
\end{abstract}

O que Shana denomina de: "estar ajudando a direção", na verdade, é fazer o trabalho de três pessoas: diretor, porteiro e secretário escolar. Isso indica que na escola de Shana, os profissionais citados: "porteiro" 
e "secretário" são ausentes ou inexistentes, obrigando os coordenadores pedagógicos a assumirem tarefas que não são de sua atribuição, mas, eles as realizam objetivando o bem da organização da escola. A legislação oficial traz como atribuições do coordenador pedagógico:

\begin{abstract}
Assessorar o diretor na coordenação e elaboração do planejamento, execução e avaliação curricular e o desenvolvimento do trabalho pedagógico em consonância com as diretrizes emanadas da Secretaria Municipal de Educação do Rio de Janeiro, de forma a atender à diversidade da escola (RIO DE JANEIRO, 1998a, p.5).
\end{abstract}

As atribuições do coordenador pedagógico são específicas da área pedagógica, e, assim como o diretor, ele também é subordinado às diretrizes da SME. Porém, devido à falta de pessoal, ou por causa do absenteísmo de professores e funcionários pelas causas mais diversas, traz como consequência, uma sobrecarga de trabalho sobre os coordenadores pedagógicos que, além das atribuições inerentes à sua função, também executam o serviço de outros profissionais. O diretor, por ocupar uma posição hierárquica superior aos demais profissionais que trabalham na escola, delega estas tarefas a seus coordenadores, utilizando-se do artifício da afetividade, ou seja, a "liderança carismática" (WEBER, apud. SOUZA, 2012) ou através do apelo de contribuir para o bom funcionamento da organização escolar.

Os coordenadores pedagógicos que declararam fazer algum tipo de trabalho administrativo mostram que o exercício destas tarefas está inserido na categoria "ajudar à direção". O coordenador, neste caso, está subordinado às decisões tomadas pelo diretor. Barroso (2005) afirma que a organização interna, gestão de pessoal, gestão financeira e representação oficial são atribuições exclusivas do diretor.

Os dilemas enfrentados pelo coordenador pedagógico no exercício de seu trabalho, revelam as dificuldades organizacionais existentes na escola pública brasileira em geral, devido à redução de investimentos no setor (CARNOY, 2002). A falta de pessoal para funções tais como: secretário escolar, agente educador, porteiro, professor, sobrecarrega o coordenador pedagógico que é obrigado a assumir diversas atividades no decorrer de seu cotidiano, diminuindo o tempo destinado às atividades exclusivamente pedagógicas e de acompanhamento da formação continuada docente. As falas das entrevistadas demonstraram que o 
coordenador exerce múltiplas tarefas: porteiro - "abro a escola e fecho a escola"; secretário escolar - "faço declaração", "atendo telefone" e "preencho o sistema acadêmico"; professor - "acabo pegando turma"; diretor-adjunto - "a gente passou sem diretor-adjunto alguns meses então eu dou apoio à diretora".

Para Oliveira (2004), os processos de flexibilização e precarização das relações de emprego e trabalho chegam também ao campo da gestão escolar. As teses sobre desvalorização e desqualificação da força de trabalho dos profissionais da educação, bem como sobre desprofissionalização e proletarização do magistério, continuam a ensejar estudos e pesquisas de caráter teórico e empírico. Tais estudos indicam que as reformas educacionais mais recentes têm repercutido negativamente sobre a organização escolar, provocando uma reestruturação do trabaIho pedagógico que resulta no aumento da carga de trabalho sobre docentes e gestores escolares.

Sobre a questão da falta de pessoal existente na escola, as causas mais prováveis parecem ser a falta de investimentos por parte do poder público na área educacional quando se refere à construção de uma escola pública que preencha os requisitos de qualidade de atendimento e funcionalidade.

As questões que envolvem as relações de poder entre o diretor e o coordenador pedagógico são resultantes da estratificação de funções desempenhadas pelos diversos profissionais que trabalham na escola. O diretor utiliza-se da dominação, que é a imposição de um comportamento a terceiros. E ainda as formas de dominação legítima são caracterizadas pela dominação racional-legal que trata do domínio sobre os regulamentos, e a dominação carismática (WEBER, apud. SOUZA, 2012), que neste caso, trata-se da obediência ao diretor, pois, ele é considerado como: um "amigo", um "aliado", um "parceiro". E esta dominação apresenta-se das formas mais diversas, sendo caracterizada, por exemplo, na categoria: "ajudar à direção".

\section{Considerações finais}

O perfil de gestão das escolas públicas municipais da cidade do Rio de Janeiro demonstra que as relações de poder entre: coordenador pedagógico-professores e, coordenador pedagógico-diretor, são exemplos de relações verticais que se estabelecem entre os diversos profissio- 
nais que trabalham na escola, conforme os entrevistados revelaram. Os relatos demonstraram que estas relações são demarcadas e estratificadas mesmo quando envolvem a afetividade na ação de liderança exercida pelo diretor sobre coordenador e professores (POLON, 2009)

Os coordenadores demonstraram que apoiam seus diretores, revelando que existe "parceria" entre a equipe gestora da escola, mas, demonstraram que, em alguns momentos, há falta de autonomia para o desenvolvimento de projetos pedagógicos e de tarefas relacionadas à formação continuada docente, sendo considerado por eles como um fator prejudicial ao desenvolvimento de seu trabalho.

Na relação estabelecida com os professores, os coordenadores pedagógicos também impõem o seu poder quando cobram ações pedagógicas de seus professores. Alguns coordenadores disseram que exercitam o seu poder sobre os docentes de forma explícita, enquanto outros afirmam que preferem conquistar o grupo docente através da liderança relacional.

A afetividade se revela como uma categoria de fundamental importância porque se torna um instrumento do qual os coordenadores se munem para tecer relações de amizade e cooperação junto aos professores e diretor, suavizando as relações hierárquicas de poder existentes na escola.

Este estudo procurou compreender as relações de poder exercidas entre coordenador pedagógico-diretor e coordenador pedagógico-professores no cotidiano escolar, demonstrando que estas relações nem sempre envolvem conflitos explícitos, mas, inclusos nas parcerias e na amizade, indicando que os relacionamentos construídos entre gestores e professores necessitam de diretrizes que tenham como referência as relações socioafetivas.

Na questão relacionada às diversas tarefas assumidas pelos coordenadores pedagógicos na rotina da escola, que não fazem parte de suas atribuições, mas, sendo de outros profissionais, trazem como consequência uma sobrecarga de trabalho sobre eles. As falas dos entrevistados demonstraram que se faz necessário uma maior distribuição de recursos humanos por parte da SME para ocupação de vagas existentes nos quadros de pessoal das escolas. Os sistemas escolares devem se empenhar na contratação de pessoal especializado e buscar o aumento de investimentos no setor, a fim de melhorar a qualidade dos serviços prestados pelas escolas públicas, no geral. 
Esperamos que este artigo possa contribuir para reflexões e pesquisas a respeito das relações de poder existentes na escola e como estas influenciam no desempenho da equipe gestora da escola frente aos desafios oriundos das políticas educacionais e os dilemas existentes no cotidiano escolar.

\section{Referências}

ASSIS, C.P;;MENDES, E.G.;ALMEIDA, M, A. Ensino colaborativo: um relato de experiência sobre o desenvolvimento da parceria colaborativa. Revista Educere et Educare Revista de Educação. Cascavel: Universidade do Oeste do Paraná, v.6, n.11, jan-jun 2011, p.1-15. Disponível em: <http:// e-revista.unioeste.br/index.php/educereeteducare/article/view/3981> Acesso em: 8 jun 2017.

BARRETO, V.S; SILVA, S.M.C. Afetividade e aprendizagem: conhecendo a prática pedagógica de uma educadora. Revista Horizonte Científico. Uberlândia: Universidade Federal de Uberlândia, v.1, p.1-23, 2006.

BARROSO, J. Políticas Educativas e organização escolar. Lisboa: Universidade Aberta, 2005.

CARNOY, M. Mundialização e reforma na educação: o que os planejadores devem saber. Brasília: UNESCO, 2002.

DEL PRETTE, Z.A.P., DEL PRETTE, A. Desenvolvimento interpessoal e educação escolar; enfoque das habilidades sociais. Revista Temas em Psicologia. São Paulo: Universidade Federal de São Carlos, v.6, n.3, 1998, p.205-215.

LÜDKE, M.; ANDRÉ, M.E.D.A. Pesquisa em Educação: abordagens qualitativas. São Paulo: Editora Pedagógica e Universitária, 1986.

LÜCK, H. Gestão educacional: uma questão paradigmática. Série cadernos de gestão. v. 1, Petrópolis: Vozes, 2006.

LÜCK, H. Liderança em gestão escolar. Série cadernos de gestão. v. 4, Petrópolis: Vozes, 2008.

OLIVEIRA, D. A. A reestruturação do trabalho docente: precarização e flexibilização. Revista educação e sociedade. Campinas: Universidade de Campinas, v. 25, n. 89, set./dez. 2004, p. 1127-1144. 
OLIVEIRA, E.; ENS, R.T.; FREIRE ANDRADE, B.S.; MUSSIS, C.R. Análise de conteúdo e pesquisa na área da educação. Revista Diálogo Educacional, Curitiba: Universidade Católica do Paraná, v.4, n.9, p.1-17, maio/ago. 2003.

OLIVEIRA, J. C. Um estudo sobre o coordenador pedagógico: sua identidade, seu trabalho e formação continuada no cotidiano escolar. Dissertação de mestrado. Rio de Janeiro: Pontifícia Universidade Católica do Rio de Janeiro, 2009.

OLIVEIRA, J. C. Os coordenadores pedagógicos de escolas públicas municipais da Secretaria Municipal de Educação da Cidade do Rio de Janeiro como mediadores das políticas curriculares. Tese de doutorado. Rio de Janeiro: Pontifícia Universidade Católica do Rio de Janeiro, 2015.

PIERRO, M. C. Descentralização, focalização e parceria: uma análise das tendências das políticas na educação de jovens e adultos. Educação e pesquisa. São Paulo: Universidade Federal de Campinas, v. 27, n. 02, p.321-337, jul./ dez. 2001.

PLACCO, V.M.N.S; SOUZA, V.L.T. O trabalho do coordenador pedagógico na visão de professores e diretores: contribuições à compreensão de sua identidade profissional. In: PLACCO, V.M.N.S; ALMEIDA, L.R. $\mathbf{O}$ coordenador pedagógico: provocações e possibilidades de atuação. São Paulo: Loyola, c.1, 2012, p. 9-20.

POLON, T. L. P. Identificação dos perfis de liderança características relacionadas à gestão pedagógica eficaz nas escolas participantes do projeto Geres - Estudo Longitudinal Geração Escolar 2005 - Rio de Janeiro. Tese de doutorado. Rio de Janeiro: Pontifícia Universidade Católica do Rio de Janeiro, 2009.

RIO DE JANEIRO. Lei 2.619 de 16 de janeiro de 1998. Dispõe sobre a estrutura organizacional, pedagógica e administrativa da rede pública municipal de educação. Diário Oficial do Rio, Rio de Janeiro: Imprensa da Cidade, ano 11, n. 210, 19 jan 1998a, p. 4-5.

RIO DE JANEIRO. Secretaria Municipal de Educação. Departamento Geral de Educação. Circular E/DGED no 37: Atribuições dos coordenadores pedagógicos de 13 de julho de 1998b. In: Curso para docentes do ensino fundamental - coordenador pedagógico. Rio de Janeiro: 
Fundação João Goulart - Prefeitura da Cidade do Rio de Janeiro, 2005. p. 8-9 (circulação interna).

SADALLA, A. M. F.; AZZI, R. G. Contribuições da afetividade para a educação. In: RIBEIRO DO VALLE, L.E.L. (Org.). Temas multidisciplinares de neuropsicologia e aprendizagem. 2.ed. São Paulo: Scortecci, v.1, 2004, p. 343-353.

SOUZA, A.R. Perfil da gestão escolar no Brasil. Tese de doutorado. São Paulo: Pontifícia Universidade Católica de São Paulo, 2006.

SOUZA, A.R. A natureza política da gestão escolar e as disputas pelo poder na escola. Revista Brasileira de Educação. v. 17, n. 49, Campinas São Paulo: Autores Associados, jan-abr 2012, p.159-174.

WEBER, M. Economia e sociedade: fundamentos da sociologia compreensiva. Brasília: Universidade de Brasília, 2009.

ZAGO, N. A entrevista e seu processo de construção: reflexões com base na experiência prática de pesquisa. In: . CARVALHO, M.P.; VILELA, R.A.T. Itinerários de pesquisa: perspectivas qualitativas em Sociologia da Educação. Rio de Janeiro: DP\&A, 2003 c. 11, p. 287-309.

Recebido em março/2017

Aceito em abril/2017 